\title{
ANGLICIZMI U SPORTU
}

\section{Jovana Radojković}

Univerzitet Singidunum,

Beograd, Srbija
Odgovorno lice:

Jovana Radojković

e-pošta:

jradojkovic@singidunum.ac.rs
Rezime:

Modernizacijom medija i stepenom dostupnosti informacija i sport dostiže nove širine na svetskom nivou čime se javlja potreba za uvođenjem novih reči u jezike kako bi se označili pojmovi vezani za sportove. Priloženi rad se bavi pregledom postojanosti anglicizama u žurnalističkom stilu srpskog jezika u oblasti sporta. Uzorak koji je obrađen sastoji se od tekstova o sportu sa internet portala srpskih aktuelnih novina. Nakon definisanja i utvrđivanja anglicizama rad se bavi razvrstavanjem priloženih primera prema načinu realizacije a zatim i različitim vidovima adaptacije u jeziku primaocu, naime na ortografskom, fonološkom, i morfološkom nivou. Zaključci koji proizilaze iz rada predstavljaju prikaz frekventnosti anglicizama u sportu u žurnalističkom stilu srpskog jezika kao i njihovu opravdanost u datim jezičkim kontekstima. $\mathrm{Na}$ kraju, postavlja se i pitanje uticaja anglicizama u sportu na nacionalni identitet, ali i ističe da sport iziskuje upotrebu anglicizama usled nastanka većine popularnih sportova upravo na engleskom govornom području.

Ključne reči:

anglicizmi, sport, žurnalistički stil, adaptacija, nacionalni identitet.

\section{UVOD}

U 20. i 21. veku koji pomeraju granice tehnološkog napretka. Razvoj tehnologije a posebno u oblasti medija i komunikacije ističe engleski jezik kao lingua franca [1]. Sport je deo svakodnevice čoveka iz više razloga, ali prvenstveno zarad poboljšanja zdravlja, vođenja zdravog života kao i uživanja u sportu kako pojedinca tako i širokoh narodnih masa. Razvojem sporta javlja se i potreba za novim rečima koje će opisivati iste. Razvoj, unapređivanje i rasprostranjenost interneta na svetskom nivou omogućavaju brz protok informacija kao i dostupnost istih na najvišem nivou. Engleske reči u srpskom jeziku sve više postaju deo naše svakodnevice usled dostupnosti jezika i izloženosti engleskom jeziku putem filmova, muzike, medija, a pre svega interneta tako da se engleski u srpskom može definisati i kao „odomaćeni strani jezik.“ [2, str. 18] Novine, poruke, telegrami koji su u prethodnom veku bili glavni izvori informacija u 21 . veku preuzimaju novu formu. Elektronske novine i poruke putem mobilnih telefona i društvenih mreža u modernom svetu postaju glavni izvori informisanja kako o lokalnim tako i o svetskim dešavanjima. Engleski je danas globalni jezik kako navodi Dejvid Kristal[1]. Sport u toj novoj 
svetskoj realnosti nije izuzetak. S toga se ovaj rad bavi novinskim člancima o sportu koji se nalaze na internet portalima srpskih novina. Priloženi rad se bavi prepoznavanjem anglicizama koji su u srpski jezik uvedeni direktno i samo iz engleskog jezika. Tema ovog rada nisu anglicizmi u žurnalističkom stilu srpskog jezika u oblasti sporta koji su poreklom iz nekog drugog jezika ali su u srpski uvedeni preko engleskog jezika pa se usled široke upotrebe smatraju anglicizmima. U ovom radu se obrađuju primeri koji su isključivo uvedeni samo i direktno iz engleskog jezika. Uzorak koji je obrađen predstavlja bazu od 5 tekstova iz srpskih aktuelnih novina koje čine Politika, Danas, Telegraf, Novosti i Sportski žurnal. Nakon definisanja anglicizama a zatim i identifikacije anglicizama u tekstovima zarad utvrđivanja njihove frekventnosti rad se bavi razvrstavanjem priloženih primera prema njihovim načinima realizacije i različitim vidovima adaptacije u sistem srpskog jezika, naime na ortografskom, fonološkom i morfološkom nivou.

\section{ANGLICIZMI U SRPSKOM JEZIKU}

Anglicizmi su „riječi preuzete iz engleskog jezika i prilagođene srpskom jeziku. Anglicizmi spadaju u srpske riječi stranog porijekla. Anglicizam u srpskom jeziku je izvjesna osobina engleskog jezika koja je prenesena u srpski jezik"[3, str. 47].

Anglicizmima su se bavili mnogi poznati autori. $\mathrm{Na}$ prvom mestu se ističe Rudolf Filipović, Tvrtko Prćić, Ranko Bugarski, Ivan Klajn itd. Filipović je renomirani jugoslovenski filolog, koji navodi da je anglicizam „svaka riječ preuzeta iz engleskog jezika koja označava neki predmet, ideju ili pojam kao sustavne djelove engleske civilizacije; ona ne mora biti engleskog porijekla, ali mora biti adaptirana prema sustavu engleskog jezika i integrirana u engleski vokabular" [2, str. 18]. Zatim, Postavlja se pitanje kako se stvaraju uslovi za pozajmljivanje reči. Rudolf Filipović navodi da se strane reči „u procesu jezičnog posuđivanja adaptiraju i integriraju u jezik primalac, pa kao posuđenice popunjuju prazna mjesta u vokabularu toga jezika"[4, str. 15]. S obzirom na podatak da se u ovom radu istražuje frekventnost anglicizama isključivo preuzetih iz engleskog jezika baveći se sportskim člancima ističe se činjenica da je fokus na rečima koje popunjavaju praznine u jeziku vezane za reči koje opisuju sportove i njihove pojmove a nastale su na engleskom govornom području. Istražuje se opravdanost upotrebe anglicizama u sportu u vidu neophodnog uvođenja istih usled nepostojanja reči koje označavaju te pojmove u srpskom jeziku.
Kada definišemo dva jezika kao jezik davalac koji daje reč i jezik primalac koji takoreći prima reč, a u našem slučaju su to engleski jezik i srpski jezik, možemo nastaviti sa razlučivanjem na koji način dolazi do promena u srpskom jeziku na osnovu uticaja engleskog jezika [5, str. 69].

Promene u srpskom jeziku u vidu uvođenja novih reči na osnovu uticaja engleskog jezika je najizraženiji vid uticaja engleskog jezika na srpski, međutim svakako ne i jedini. Taj uticaj se može uočiti na svim jezičkim nivoima: pisanja, izgovora, gramatike, semantike i pragmatike [2, str 78-84].

Svi primeri su prvenstveno provereni u rečniku[6] a nakon što je utvrđeno da su priložene reči zaista anglicizmi koji su u srpski jezik ušli direktno iz engleskg jezika pristupljeno je daljoj analizi pojedinačnih primera na osnovu načina realizacije da bi se docnije pristupilo utvrđivanju nivoa adaptacije datih anglicizama u srpski jezik.

Veliki broj pozajmljenica čine reči koje su sastavni deo struke odnosno posebnih struka i s toga je to jezik za posebne namene. Jezik struke kojim se ovaj rad bavi je jezik sporta. U najvećem broju slučajeva to su internacionalizmi koji potiču iz latinskog kao i grčkog jezika [7, str. 134-135]. U ovom radu nisu uzeti u obzir anglicizmi koji su poreklom iz nekog drugog jezika a u srpski jezik su ušli putem engleskog jezika. Fokus ovog rada su anglicizmi u sportu koji potiču iz engleskog jezika.

Važno je naglasiti da se ovaj rad neće baviti semantičkom i pragmatičkom analizom.

\section{KLASIFIKACIJAANGLICIZAMA PREMA NAČINU REALIZACIJE [2]}

Anglicizmi se prema načinu realizacije mogu svrstati u tri različite grupe i to su: očigledni, skriveni i sirovi anglicizmi. [2, str. 121-123]

- Očigledni anglicizmi su reči preuzete iz engleskog jezika čije se poreklo odmah može zaključiti na osnovu oblika datih reči.

- Skriveni anglicizmi su reči koje poseduju principe građenja reči ili neku drugu odliku engleskog jezika koja je zadržana i u srpskom jeziku.

- Sirovi anglicizmi su reči ili fraze koje su iz jezika davaoca direktno prenete u jezik primalac bez ikakvih promena. Takvi anglicizmi se u srpskom jeziku pišu istovetno kao i u engleskom, u svom izvornom obliku, i ne uklapaju se u način upotrebe u srpskom jeziku. 


\section{ADAPTACIJA ANGLICIZAMA}

Kao što je ranije navedeno brojni renomirani autori su se bavili istraživanjem i definisanjem nivoa adaptacije anglicizama u srpskom jeziku. Vrste adaptacije anglicizama koriščeni za potrebe ovog rada predstavljaju ortografski, fonološki i morfološki nivo za analizu anglicizama u žurnalističkom stilu srpskog jezika u tekstovima o sportu.

\section{Adaptacija anglicizama na ortografskom nivou}

Oblici adaptacije engleskih reči u srpski jezik na osnovu pravila pisanja su sledeći [2, str. 78-80]:

- kada se reč piše na latinici i zadržava originalni oblik, istovetan oblik kao u engleskom jeziku

- prenošenje pojedinačnih slovnih vrednosti iz engleskog na srpski sa naglaskom da je u pitanju latinično pismo. Međutim, kada to nije moguće jer ne postoji odgovarajući ekvivalent u srpskom jeziku onda se vrši zamena, odnosno uzima slovna vrednost koja je najsličnija originalu.

- približnom transkripcijom

\section{Adaptacija anglicizama na fonološkom nivou[8]}

Fonološka adaptacija je „zamena fonoloških elemenata jezika davaoca elementima jezika primaoca, a javlja se u toku formiranja fonološkog oblika posuđenice u jeziku primaocu" [9, str 69]. Postoje 3 nivoa transfonemizacije odnosno adaptacije anglicizama na osnovu izgovora i to su: nulta, delimična i slobodna.

- Nulta transfonemizacija predstavlja istovetan izgovor anglicizma kako u jeziku davaocu tako i u jeziku primaocu. $\mathrm{U}$ tabeli 3. su navedene primeri nulte transfonemizacije anglicizama u sportu $\mathrm{u}$ žurnalističkom stilu srpskog jezika.

- Delimična transfonemizacija predstavlja adaptaciju anglicizma kada se njegov izgovor u jeziku primaocu delimično poklapa sa njegovim originalnim izgovorom, odnosno izgovorom $\mathrm{u}$ jeziku davaocu. $U$ tabeli 4 . su navedeni primeri delimične transfonemizacije anglicizama u sportu u žurnalističkom stilu srpskog jezika.

\begin{tabular}{ccc}
\hline $\begin{array}{c}\text { Očigledni } \\
\text { anglicizmi }\end{array}$ & $\begin{array}{c}\text { Skriveni } \\
\text { anglicizmi }\end{array}$ & $\begin{array}{c}\text { Sirovi } \\
\text { anglicizmi }\end{array}$ \\
\hline gol & lov & top \\
\hline dres & & super \\
\hline tim & & \\
\hline blok & & \\
\hline
\end{tabular}

Tabela 1. Klasifikacija anglicizama po obliku [10], [11], [12]

\begin{tabular}{cc}
\hline $\begin{array}{c}\text { Primeri na engleskom } \\
\text { jeziku - jeziku davaocu }\end{array}$ & $\begin{array}{c}\text { Primeri na srpskom } \\
\text { jeziku - jeziku primaocu }\end{array}$ \\
\hline starter & starter \\
set & set \\
top & top \\
\hline derby & derbi \\
\hline football & fudbal \\
club & klub \\
\hline
\end{tabular}

Tabela 2. Adaptacija anglicizama na ortografskom nivou [10], [11], [12],[13], [14]

\begin{tabular}{cc}
\hline $\begin{array}{c}\text { Primeri na engleskom } \\
\text { jeziku - jeziku davaocu }\end{array}$ & $\begin{array}{c}\text { Primeri na srpskom } \\
\text { jeziku - jeziku primaocu }\end{array}$ \\
\hline block & blok \\
\hline play-off & plej-of \\
\hline match & meč \\
\hline
\end{tabular}

Tabela 3. Klasifikacija anglicizama na osnovu nulte treansfonemizacije u okviru fonloške adaptacije [10], [11], [14]

\begin{tabular}{cc}
\hline $\begin{array}{c}\text { Primeri na engleskom } \\
\text { jeziku - jeziku davaocu }\end{array}$ & $\begin{array}{c}\text { Primeri na srpskom } \\
\text { jeziku - jeziku primaocu }\end{array}$ \\
\hline footballer & fudbaler \\
\hline playmaker & plejmejker \\
\hline
\end{tabular}

Tabela 4. Klasifikacija anglicizama na osnovu delimične transfonemizacije u okviru fonološke adaptacije [12], [13]

\begin{tabular}{cc}
\hline $\begin{array}{c}\text { Primeri na engleskom } \\
\text { jeziku - jeziku davaocu }\end{array}$ & $\begin{array}{c}\text { Primeri na srpskom } \\
\text { jeziku - jeziku primaocu }\end{array}$ \\
\hline team & tim \\
\hline goal & gol \\
\hline shoot & šut \\
\hline
\end{tabular}

Tabela 5. Klasifikacija anglicizama na osnovu slobodne treansfonemizacije u okviru fonloške adaptacije

[11], [12], [13], [14] 
- Slobodna transfonemizacija označava adaptaciju anglicizama pri čemu ne postoji odgovarajuća fonema u fonetskom sistemu jezika primaoca koja bi zamenila datu fonemu iz jezika davaoca. Najistaknutinji primeri ove grupe su diftonzi engleskog jezika koji nemaju ekvivalent u srpskom fonološkom sistemu. U tabeli 5. su navedeni primeri delimične transfonemizacije anglicizama u sportu u žurnalističkom stilu srpskog jezika.

\section{Adaptacja anglicizama na morfološkom nivou}

Adaptaciju anglicizama na morfološkom nivou odlikuje dodavanje afiksa (prefiksa i sufiksa) u vidu da li se reč prenosi u svom osnovnom obliku ili sa postojećim afiksom, kao i da li afiks ima značenje u jeziku primaocu nakon adaptacije u tom obliku. Takođe, adaptaciju anglicizama na morfološkom nivou karakteriše i postojanje mogućnosti dodavanja afiksa jezika primaoca i njegovo korišćenje u jezičkom sistemu jezika primaoca [8, str. 35], što je u priloženom slučaju srpski jezik. Postoje tri vrste transmorfemizacije odnosno zamene morfema anglicizama iz jezika davaoca u jezik primaoca i to su: nulta, kompromisna i potpuna. [15, str. 66]

- Nulta transmorfemizacija je zamena na morfološkom nivou kada se morfema iz jezika davaoca prenosi u jezik primalac u svom osnovnom obliku bez dodavanja afiksa jezika primaoca. U tekstovima analizirnim za potrebe ovog rada nalaze se samo dva primera nulte transmorfemizacije pri adaptaciji anglicizama u srpski jezik i to su na prvom mestu pridev super u sintagmi super liga[13] (super league) što se u tekstu menja u superligaški pri čemu super ostaje nepromenjen. Zatim, primer „top 8 faza“[11] uz napomenu da top ne menja svoj oblik u drugim kontekstima.

- Kompromisna transmorfemizacija predstavlja vid adaptacije kada morfema pri adaptaciji iz jezika davaoca u jezik primalac zadrži svoj afiks. Međutim, taj afiks biva adaptiran na fonološkom nivou dok to nije slučaj i na morfološkom, odnosno ne poštuju se morfološka pravila jezika u koji se anglicizam adaptira kao u primerima starter - starter[12], i playmaker - plejmejker[13].

- Potpuna transmorfemizacija pretstavlja process adaptacije morfeme jezika davaoca tako da joj se može dodati vezana morfema jezika primaoca odnosno nastavak srpskog jezika kao u primerima direct - direktan[11], i shoot - šutirati.[12]

\section{REZULTATI}

Za priloženo istraživanje nije korišćen kompjuterski softver već je rađeno manualno. Na osnovu obrađenog korpusa od 5 tekstova[10], [11], [12], [13], [14] koji se sastoje od 1286 reči dolazi se do sledećih zaključaka. Među primerima u definisanom korpusu identifikovano je ukupno 75 anglicizama što čini 5.8\% reči od ukupnog broja reči u tekstovima. Ukupno 56 anglicizama u tekstovima su u srpski jezik iz engleskog kao jezika davaoca usvojeni putem procesa adaptacije. Taj broj predstavlja $4.3 \%$ reči od ukupnog broja reči u tekstovima. Od navedenih vrsta anglicizama po načinu realizacije rezultati su sledeći: najfrekventniji anglicizmi su očigledni anglicizmi i oni čine $1.2 \%$ ukupnog broja reči u tekstovima. Zatim slede skriveni i sirovi anglicizmi sa po $0.15 \%$ zastupljenosti u tekstovima. Anglicizmi koji su u srpski jezik uvedeni putem procesa adaptacije čine $1.3 \%$. Najzastupljeniji su anglicizmi koji su adaptirani na fonološkom nivou i čine ukupno $0.8 \%$ Anglicizmi koji su u srpskom jeziku adaptirani na morfološkom nivou čine $0.5 \%$. Anglicizmi koji su adaptirani na ortografskom nivou su najmanje zastupljeni i to sa $0,06 \%$. Na osnovu priloženih rezultata može se zaključiti da anglicizmi koji su u srpski jezik adaptirani putem ortografske, fonološke kao i morfološke adaptcije nisu veoma frekventni u sportskim časopisima internet portala srpskih novina.

\section{OPRAVDANOST UPOTREBE ANGLICIZAMA}

Nakon definisanja anglicizama u tekstovima o sportu sa internet portala srpskih novina i njihovog razvrstavanja može se zaključiti da na uzorku od 5 ponuđenih tekstova u žurnalističkom stilu postoji upotreba anglicizama. Anglicizmi u sportu u žurnalističkom stilu srpskog jezika su prisutni ali i neophodni jer se u najvećoj meri koriste u odgovarajućem kontekstu usled činjenice da u srpskom jeziku ne postoje odgovarajući ekvivalenti. Anglicizmi u sportu su opravdani u kontekstu kada ne postoji odgovarajuća reč na srpskom jeziku ili kako se ne bi koristio iznimno veliki broj reči zarad opisa i na taj način se vodilo računa i o ekonomičnosti jezika. Takvu praksu predstavljaju sledeći primeri: blok i set u odbojci, plejmejker u košarci i fudbaler u fudbalu. Međutim, prisutni su i anglicizmi koji se koriste u kontekstu u kojem ipak postoji ekvivalent na srpskom jeziku što takvu upotrtebu čini neopravdanom i to je primeri na engleskom play-of za koji se na srpskom koristi plej-of umesto doigravanje. Na osnovu priloženih rezultata nameće se zaključak da su anglicizmi opravdano upotrebljivani u datim kontekstima u člancima o sportu. 


\section{UTICAJ ANGLICIZAMA NA NACIONALNI INTEGRITET I JEZIČKI PURIZAM}

Ivan Klajn navodi da srpski jezik ima tendenciju lakog prihvatanja pozajmljenica. Takođe, iznosi stav da ne treba oživljavati arhaizme niti graditi veštačke kovanice isključivo sa ciljem da se izbegne uvođenje pozajmljenica u izvroni jezik.[16, str. 153] Stav autora ovog rada jeste da treba pratiti moderne tokove i ići u korak sa praćenjem napretka i originalnih izuma. Da ne treba zaostati usled nepostojanja odgovarajućih reči u jeziku u datom trenutku. Iz tog razloga treba adaptirati anglicizme u sportu zarad obogaćivanja jezika i potrebe za imenovanjem sportskih pojmova. Međutim, nije neophodno niti potrebno upotrebljavati anglicizme ukoliko postoji ekvivalentan izraz na srpskom jeziku i na taj način istovremeno i negovati srpski jezik uz upotrebu domaćih reči. Međutim, ukoliko reč u jeziku ne postoji opravdano je preuzeti reč iz stanog jezika. U svetu sporta to je u najvećoj meri engleski jezik jer je većina popularnih sportova upravo nastala na engleskom govornom području. Takođe, na osnovu rezultata iz kojih proističe da anglicizmi u sportu u žurnalističkom stilu srpskog jezika nisu u velikoj meri frekventni izvodi se zaključak da samim tim i ne utiču negativno na jezik i integritet. Nasuprot tome, pomažu jeziku primaocu da obogati svoj fond reči u vidu jezika za posebne namene što je u datom slučaju jezik sporta.

\section{ZAKLJUČAK}

Izloženost engleskom jeziku u moderno doba putem modernih medija utiče na srpski jezik na svakodnevnom nivou. Kako su vremenom nastajali novi sportovi na engleskom govornom području javljala se potreba za uvođenjem i formiranjem novih reči za njihove opise. $S$ toga se putem ortografske, fonološke i morfološke adaptacije anglicizama obogaćuje srpski jezik terminima koji u suprotnom slučaju ne bi postojali u srpskom jeziku. $U$ tom slučaju bi srpski jezik ostao uskraćen za određeni fond reči za posebne namene. Opravdano je korišćenje anglicizama u sportu u žurnalističkom stilu srpskog jezika na osnovu tekstova sa internet portala srpskih novina ukoliko ne postoje ekvivalentni termini za date termine u sportu u srpskom jeziku. Ovaj rad ukazuje na prisutnost anglicizama koji su u srpski jezik adaptirani na ortografskom, fonološkom i morfološkom nivou ali ne i na njihovu veliku frekventnost. To ukazuje na konstataciju da postoji opravdana upotreba anglicizama. Nije opravdana prekomerna upotreba anglicizama ukoliko postoje odgovarajuće reči u srpskom jeziku što se na osnovu priloženog istraživanja nije pokazalo. $\mathrm{Na}$ osnovu obrađenih tekstova anglicizmi u sportu u žurnalističkom stilu jesu prisutni, nisu izrazito frekventni ali su nadasve opravdani jer označavaju pojave i radnje za koje ne postoji ekvivalent u srpskom jeziku.

\section{LITERATURA}

[1] D. Crystal, "English as a global language", Cambridge: Cambridge University Press, 2003.

[2] T. Prćić, „Engleski u srpskom”. Novi Sad: Zmaj, 2005.

[3] M. Vujaklija, Leksikon stranih reči i izraza, Beograd, 1980.

[4] R Filipović, „Anglicizmi u hrvatskom ili srpskom jeziku: porijeklo, razvoj, značenje. Zagreb: Jugoslavenska akademija znanosti i umjetnosti -Školska knjiga, 1990.

[5] A. Calabrese, W. L. Wetzels, "Loan Phonology", John Benjamins Publishing Co, The Netherlands: Amsterdam, 2009.

[6] M. Šipka, I. Klajn, „Veliki rečnik stranih reči“, 2011.

[7] Ž. Stanojčić, Lj. Popović, „Gramatika srpskog jezika“, Zavod za udžbenike nastavna sredstva, Beograd, 2002.

[8] R. Filipović, „Neposredni jezički dodiri u hrvatskim dijalektima u SAD", Izvorni znanstveni rad, UDC: 800.874.:808.62(73), UR: 1991-09-08.

[9] R. Filipović „Teorija jezika u kontaktu: uvod u lingvistiku jezičkih dodira“, Zagreb, 1986.

[10] „Pregled kola: Velika pobeda jedinstva, Zvezda na čelu tabele", http://www.zurnal.rs/odbojka/superliga/55732/pregled-kola-velika-pobeda-jedinstvazvezda-na-celu-tabele, [Mart 28, 2018]

[11] „Fenerbahče bolji od Himkija, PAO okrenuo protiv Reala", http://www.zurnal.rs/kosarka/evroliga/56548/fenerbahce-bolji-od-himkija-pao-okrenuo-protiv-reala-video, [Mart 28, 2018]

[12] „Radonjić oprezan pred Mladost: Biće to pravi mali derbi" http://www.novosti.rs/vesti/sport.434. html:719237-RADONjI\%C4\%86-OPREZANPRED-MLADOST-Bi\%C4\%87e-to-pravi-maliderbi, [Mar 29, 2018]

[13] „Tri srpska kluba se bore za plej-of”, http://www. politika.rs/scc/clanak/400915/Sport/Kosarka/Trisrpska-kluba-se-bore-za-plej-of, [Mart 29, 2018]

[14] „Rukometašice Srbije izgubile od Švedske golom u poslednjoj sekundimeča",http://www.telegraf.rs/ sport/ostali-sportovi/2945591-rukometasice-srbijeizgubile-od-svedske-golom-u-poslednjoj-sekundimeca [Mart 29, 2018] 
[15] K. Ćirić-Duvnjak, Stručni članak „Uloga anglicizama u sportskoj terminologiji srpskog jezika", SPORT - Nauka i praksa, Vol. 3, No1, 2013.
[16] I. Klajn, „Purizam i antipurizam u srpskom jeziku”, Južnoslovenski filolog, Beograd, 2008. 